\title{
Reflections on the Training of Primary School Teachers in Poor Areas under the Core Literacy
}

\author{
Zeng Bi \\ Pre-school Education College, Longnan Teachers' College, 742500
}

Keywords: core literacy; poor areas; excellent primary school; excellent teachers; training strategies

\begin{abstract}
With the development of China's education and the deepening of educational reform, the whole society has a high expectation for the training of "excellent" teachers. The so-called "excellent" teachers refer to teachers who constantly seek breakthroughs in their positions, so as to become better qualified talents for social development ${ }^{[1]}$. And this paper carries out all-round views and analysis on excellent primary school teachers in poor areas mainly in the view of core literacy.
\end{abstract}

\section{Introduction}

With the development of the times, "core literacy" has become a key vocabulary in all the fields of education. The "core literacy" of teachers and students has become a very important issue in the current environment. On this basis, how to carry out a comprehensive discussion about the core literacy of teachers has become a very concerned question [2]. From the perspective of core literacy, what core qualities a teacher should possess as an excellent teacher has become a problem that everyone is very concerned about and needs to discuss.

\section{Concept of Core Literacy}

The "core literacy" industry was originally produced in the field of education, in order to solve the "why we teach" and exist. We are all around "how to teach", including the recent popular "reverse class" and "mousse". Because people must set a clear direction in their life, if the direction is wrong, then it will make you leave your goal more and more far. Therefore, when the concept of core literacy is applied to teachers, let us know better how to cultivate an excellent and excellent teacher.

"Core literacy" attempts to help teachers better solve the problem of how to improve the quality of teachers from the top level. Its appearance makes the quality of the teacher's development become more comprehensive and systematic. The relevant requirements that it will become an excellent teacher is specifically transformed into specific character and specific ability requirements, which are further integrated into the teacher's body, and tell us how we can better train an excellent teacher.

\section{Training Plan for Excellent Teachers}

With the continuous development of social economy and higher education, the competition of teachers' industry is becoming more and more intense. The number of teachers in many places is even becoming less and less [3]. The demand for outstanding teachers in the whole society is becoming higher and higher. And the plan to cultivate excellent teachers coincides with our country's "talent power plan". At the same time, talents training plan including "excellent lawyer", "excellent engineer", "excellent doctor" and other industries is also becoming more and more important. As early as 2012, China has published a number of lists of professional talents, including 368 undergraduate majors and 98 master level students in 135 universities.

As the competition of the teacher industry becomes more and more intense, many teachers in normal colleges have put forward the training plan of excellent teachers across the subject. And this 
huge planning system has been incorporated into the "12th Five-Year" development plan of our country. It is believed that with the fact of the "excellent teacher" program, there will be a better platform for teacher training in the future, [4]. The so-called "excellent teachers" training plan mainly includes the following points,first, all outstanding teachers' training plan contains almost many aspects of our subject, so we must also tell the combination of theory and practice to realize in the process of training; second, in the process of carrying out the excellent teacher training program in in particular, most of the higher education resources are fully integrated, and make it better use; third, we can see that in the process of "excellent teacher" training, for the future of education also has a very big advantage, and even can be said to be the foundation for the future to build a high quality teacher the team play very good; Lastly, in the "excellent teacher" program, each subject teachers are required to learn more knowledge, and this interdisciplinary Exchange and integration will be the development of teachers themselves have more benefits, the gap between professional and professional teachers will be broken, also in this process have more solid knowledge of the future development of education and the comprehensive development of students have a very high effect.

\section{The “Core Literacy" that Excellent Teachers Should Possess}

As more and more people attach importance to the core literacy, the core literacy of excellent teachers has also been more and more extended to the specific teachers. If we want to make our future education quality more up, then the training of teachers' core literacy is a very important part of it. This article mainly analyzes the composition of the core literacy from the following aspects:

\subsection{Education belief}

The so-called educational belief refers to the unshakable belief that teachers have in the process of education. The teacher should have the personality of love, respect and independence in the course of education. On the one hand, in the process of education, teachers should not only take students' national character and personality into consideration, but also care for students from two aspects of life and learning, and even be intimate friends of [5]. In addition, teachers should constantly update their thoughts and thinking according to the development of the times, and strive to keep pace with the times. So, in order to become an excellent teacher, the belief in education is the most fundamental quality.

\subsection{Professionalism}

If a teacher wants to do a better job at education, be sure to become more professional. In the aspect of education students, the teacher must learn to use education, psychology and other aspects of knowledge to arm themselves, also must learn to better to learn at ordinary times, such ability can have good education effect. In addition, teachers must through reading, travel and other ways to enrich my life and my heart, and in the process, constantly enrich their own knowledge structure and enrich their mind [6].Only in this way can we adopt different teaching methods according to the characteristics of each student in the course of teaching, and finally produce the students who are truly "outstanding". Therefore, high-quality "professional quality" is an indispensable part of teachers' core competence.

\subsection{Innovative spirit}

In the analysis of "excellent teacher" plan, as a good teacher, especially can not stick on the teaching methods, the outstanding teachers of excellence, is entirely because they can in the process of teaching is not satisfied with the status quo, and to take corresponding measures according to the actual situation, reform of teaching plan and accomplish the task of teaching in the last [7]. In addition, the director must Bo house at once, to learn from the theory of human experience, and after the experience of the combination, only in this way can a set of research in the development of theory and research results. The consciousness of innovation has always occupied a very important position in the cultivation of "excellent teachers". 


\subsection{Reflection ability}

It is common that every teacher will encounter various difficulties in the course of teaching. In the "excellent teacher" training program, teachers are usually very good at summing up the experience and lessons, and thus can lay a better foundation for the future teaching. In particular, teachers should analyze the causes of gaps in the teaching process to help them improve their teaching quality. Only by constantly reflecting on the gap between ourselves and the teachers with good teaching quality can we better compensate for our shortcomings and improve our own quality. Excellent teachers will be particularly involved in education and teaching process to incorporate their thinking and unique insights into education. Therefore, if a teacher wants to make his teaching quality better, he should learn to reflect in time.

\section{Strategies for the Cultivation of Primary School Teachers in the Field of Core Literacy}

\subsection{Recruit truly excellent teachers to join the teaching staff to provide better assurance for the development of education}

"Excellent teacher" is mainly embodied in the ability of a teacher to improve his wisdom through practice and study in daily life [8]. Especially in the poor areas of western China, a good teacher should not only be able to teach students more comprehensive theoretical knowledge, but also be able to better teach students some professional skills. Even some teachers should learn to encourage students so that they can get out of the mountains. In particular, some excellent local and middle school teachers can be selected to join the teaching staff in the poor areas of western China, and let these teachers better guide students in teaching and practice.

\subsection{Build a professional training platform for practical training and form a professional rising channel}

For better cultivation of "excellent primary school teachers" program at poor areas in our country, so our country's education sector has to attach more importance to students' basic vocational skills training. At present, China's higher education in the west of the school has also been carried out about the "higher school teaching quality and teaching reform project" requirements, to provide more rich resources for the teaching practice of our country.

However, since the construction of higher education in the poverty-stricken areas in western China has obviously lagged behind, there are still many problems in the process of construction. For example, in the western part of China, there are many problems such as teaching resources and allocation, backward teaching practice and many other problems. These problems will cause the relevant teaching strategies cannot be implemented effectively in the process of teaching, so as to impede the cultivation of primary school teachers of "excellence" plans in the western region.

\subsection{Develop appropriate training measures and methods}

In the poor areas of western China, the corresponding goals and methods should be set up, so that teachers can have higher teaching ability in daily life. It would be better in the western poverty-stricken areas to cultivate students to give each of the students in the process of configuration two guidance teacher, so let the school teacher is responsible for the cultivation of the students basic knowledge ability, outside the school teacher is responsible for training the students' practical ability [9]. And in the final from the teachers' teaching skills, education research ability, innovation ability and other aspects of setting appropriate goals for culture, so can truly cultivate all-round development with excellent ability of teachers.

In addition, because conditions are tough, in the west of the teachers in the process of training should join including music basic course, basic course of fine arts, classic appreciation courses and other eloquence, the way to improve the comprehensive quality of teachers has great benefits. Especially in the poor areas of the west, these courses can help teachers better adapt to the needs of work in the future work. Under the core literacy horizon for excellence in poverty-stricken areas in the process of primary school teachers to cultivate, outstanding teachers' core quality must be able 
to better adapt to the change of education ideas and values. Teachers in the process of teaching should all-round learning and thinking the value of relevant knowledge, curriculum, teaching value and the value of education, which is the only way to be able to better construct the concept of lifelong learning, it also can only in the last more enables the education career to achieve better development.

In our country for more than 30 years in poor areas of excellence primary school teachers to adapt to the curriculum and the process of continuous reform, in fact every phase of the curriculum reform puts forward a new professional development requirements for teachers, as well as the critical quality of the teachers. In the process of education and teaching practice, we must let the relevant personnel and the local government to conduct a comprehensive cooperation, and on this basis to establish a regional education cooperation alliance, so as to better promote the reform of talent in our country.

\subsection{Cultivate double circulation talent with the character of "theory with practice"}

Because the western education resources in China is generally very scarce, so in the training plan of "excellent teacher", not only need to be confined to one of the teachers some aspect knowledge or skills, but to allow the development of teachers as a whole have become very remarkable [10]. So, if you want to in the western poverty-stricken areas for the cultivation of primary school teachers, then it must be, before the entry into the secondary and develop all-round after induction, to create a "theory with practice" binary mode, only in this way can form an all-weather open personalized practice patterns.

In particular, we need to innovate a method of education practice under the original education practice mode, so as to better strengthen the proportion of teaching practice in the cultivation of teachers. It can also enable students to supervise teachers' teaching process so as to form a mode of teaching reflection on problems arising from education practice, which is also a kind of supervision for teachers. In such a virtuous circle, it is believed that more teachers will be willing to join the "excellent teachers" in the poor areas of western China in the future.

\section{Conclusion}

With the development of world economy and the continuous adjustment of industrial structure, our country's higher education is increasingly popular; the development of various professional and also will become more and more fierce competition; countries and even the teachers troop to the western region to adjust again, and a lot of primary school education professional structure will also occur within the profound changes. In addition, we pay particular attention to through continuous grab and grasp the historical opportunity to enhance remarkable talent cultivation, and in the final build a remarkable talent cultivation system, eventually making elementary school teacher's academic ability and practice ability can realize the two-way development. In particular, we should attach great importance to the the proposition of "core literacy", and standing at a new historical height to continuously seek new heights of primary school teachers cultivate excellence in poverty-stricken areas, in the long run better enhance the essence of "people power", which enables the teacher to develop better quality. In particular, we should grasp the relationship between the cultivation of excellent teachers and the core quality, so as to better write a new chapter of China's education. The author also hopes that this article can better construct the core quality of teachers in the western region, and make more and more people pay attention to this great project of core accomplishment.

\section{Acknowledgement}

The action research on" the general excellence primary school teachers "supported by the items on the universities of Gansu province. (The items number:2016A-138) 


\section{References}

[1] Xiaoyan Li. The improvement of teacher education quality depends on the multi-party cooperation among universities, primary and secondary schools and the government [J]. Chinese Teacher, 2014 (3): 58-62.

[2] Lu Huang, Jianyin Liu. Study on the professional characteristics and growth path of excellent teachers in primary and secondary schools [J]. China Education Journal, 2014 (3): 98-102.

[3] Xiangming Chen. How teachers make qualitative research [M]. Beijing: Education Science Press, 2013 (6): 69-72

[4] High level. Cai Yuanpei's annual spectral composition (middle) [M]. Beijing: People Education Publishing House, 2013(5):97-03.

[5] Jianchao Yu. Construction of a practical teaching system for innovative talent cultivation [J]. China Higher Education, 2015 (5): 53-55.

[6] Lei liu, Weili Fu. Practical ability: meaning, structure and training countermeasures [J]. Education Science, 2012 (2): 55-57.

[7] Zhanyong Qi. Rationality of the growth of the professional competence of excellent teachers [J]. Contemporary Teacher Education, 2014, (7): 43-45.

[8] Tiefang Liu. Feelings of life and education feelings [J]. Journal of social science, Hunan Normal University,2012(5):65.

[9] Jinggang $\mathrm{Bi}$, background, connotation and implementation strategy of Han Ying's "excellent teacher" plan [J]. Education Exploration, 2013, (12): 110-111.

[10] Xin Tao, Yu Jiang, Chongde Lin, Baoguo Shi, Xia Liu. On the connotation and framework of student development core literacy [J]. China education journal, 2016, (06):38-42. 